Supplement of Hydrol. Earth Syst. Sci., 22, 2041-2056, 2018

https://doi.org/10.5194/hess-22-2041-2018-supplement

(c) Author(s) 2018. This work is distributed under

the Creative Commons Attribution 4.0 License.

(c) (1)

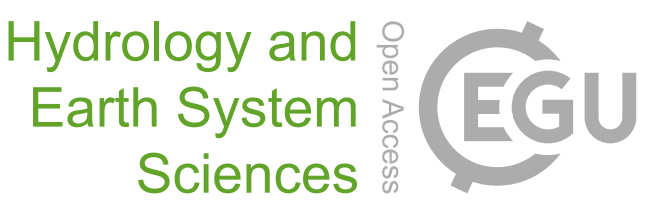

Supplement of

\title{
Increase in flood risk resulting from climate change in a developed urban watershed - the role of storm temporal patterns
}

Suresh Hettiarachchi et al.

Correspondence to: Ashish Sharma (a.sharma@unsw.edu.au)

The copyright of individual parts of the supplement might differ from the CC BY 4.0 License. 


\section{Supplemental Information}

The following is additional information related to the main body of the paper. Section 1 describes the background information and the model build process. Section 2 relates to the additional climate change scenario analysed to look at impacts to flooding. Section 3 gives the percent change in flooding at all the reference nodes.

\section{Model Background and Development}

The H/H model used in this study was developed by HDR Engineering Inc. for the South Washington Watershed District (SWWD) in the State of Minnesota, USA for the management of surface water flows and as well as for planning and management of on-going development work and capital improvement projects. The catchment area of the SWWD is a developed urban/suburban area and extends over $140 \mathrm{~km}^{2}$. Figure 1 represents the extents of the SWWD along with the extents of the complete model. Figure 2 shows the EAP-SWMM model of the area used for the current study.

The model was initially built in year 2000 and has been continuously maintained and updated with the latest available landuse/land cover and stormwater infrastructure information. The model build and background data is managed and maintained within the GIS environment as a Geodatabase and is then exported to XP-SWMM or EPA SWMM model files to execute the runs. The model includes extensive detail of all landuse types and stormwater infrastructures including sewers, culvert crossing, open channel reaches, and constructed as well as natural storages. Highly detailed delineation of both sub-catchment boundaries and impervious area was done using a high resolution Digital Elevation Model (DEM), development construction and grading plan overlays and aerial imagery within a GIS environment. All surface runoff is fed into the appropriate inflow points of the hydraulic conveyance system. Multiple layers of information were used in a GIS environment to develop characteristic percentages of impervious based on the built environment within each of the sub-catchments. By discretising to small areas, the model then is able to isolate the various landuse types within each catchment and generate a composite impervious percentage and a rate of runoff representative of each different landuse type. Local constructed storage refers to stormwater ponds that were built as part of rate and volume controls to meet post development rules requirements. Natural storage locations refer to existing ponds and lakes within the catchments. The storage information is added into the model as depth/area tables using the 
DEM and bathymetric survey (major storage locations) for natural storage locations and construction plans for constructed storage locations. Figure 3 provides and example of such development plans used as background data to build the model. Figure 4 is an example of a layer of the landuse information used to generate runoff parameters.

The selection of the 50-year event presented in this paper is a result of recent updates to the rainfall depth in NOAA Atlas 14. All throughout the period since building the model, the results that were presented were for the prevailing 100-year 24-hour rainfall event for that catchment (100-year selected to set base flood elevation for the open water areas within the catchment). Atlas $14 \mathrm{~V} 8$ updated the rainfall and increased the new 100-year rainfall depths such that previous 100 -yr rainfall depth is now the 50-year rainfall depth. 


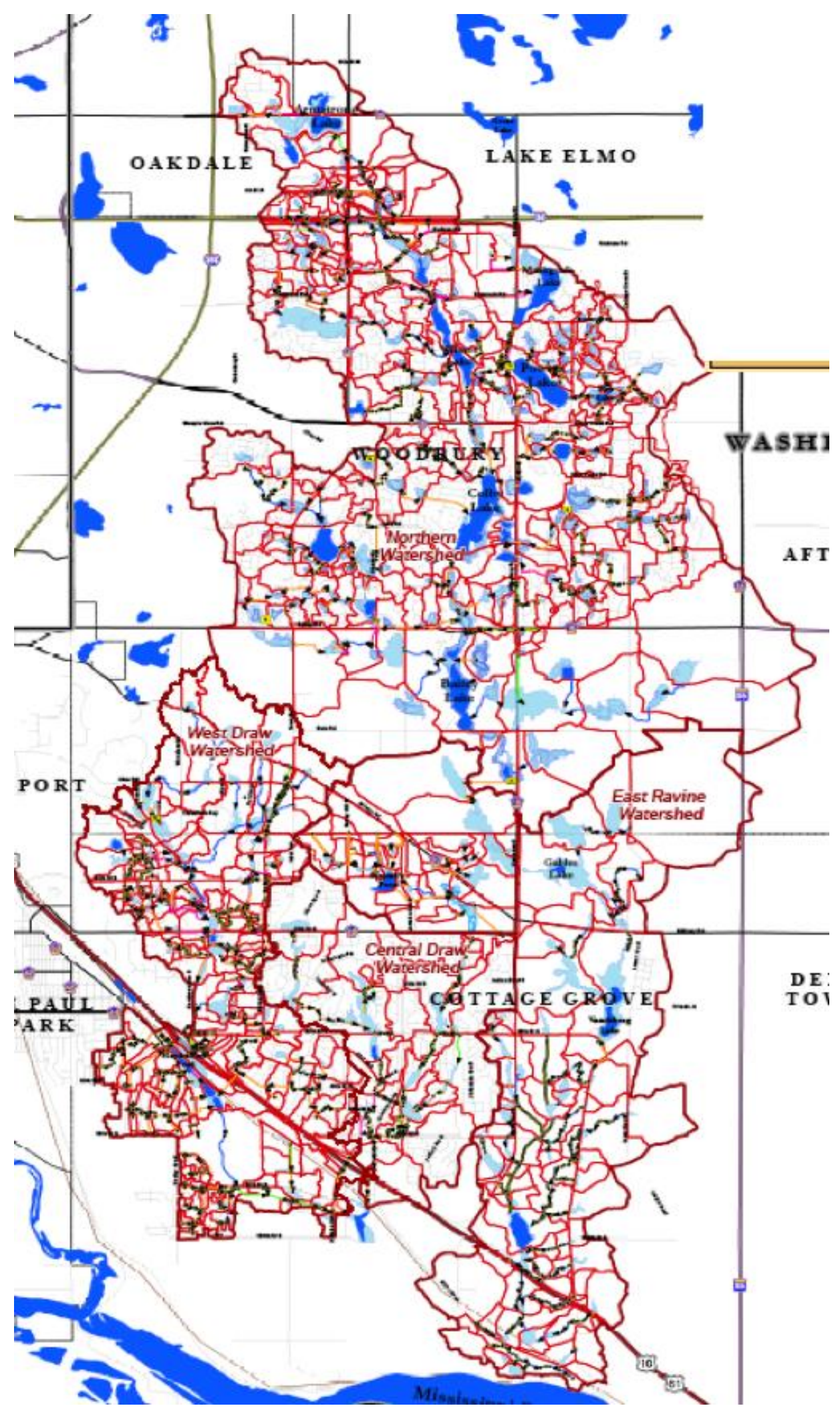

Figure 1. The complete extent of the South Washington Watershed District (For illustration only) and view of the model extent and major/minor subwatersheds. 


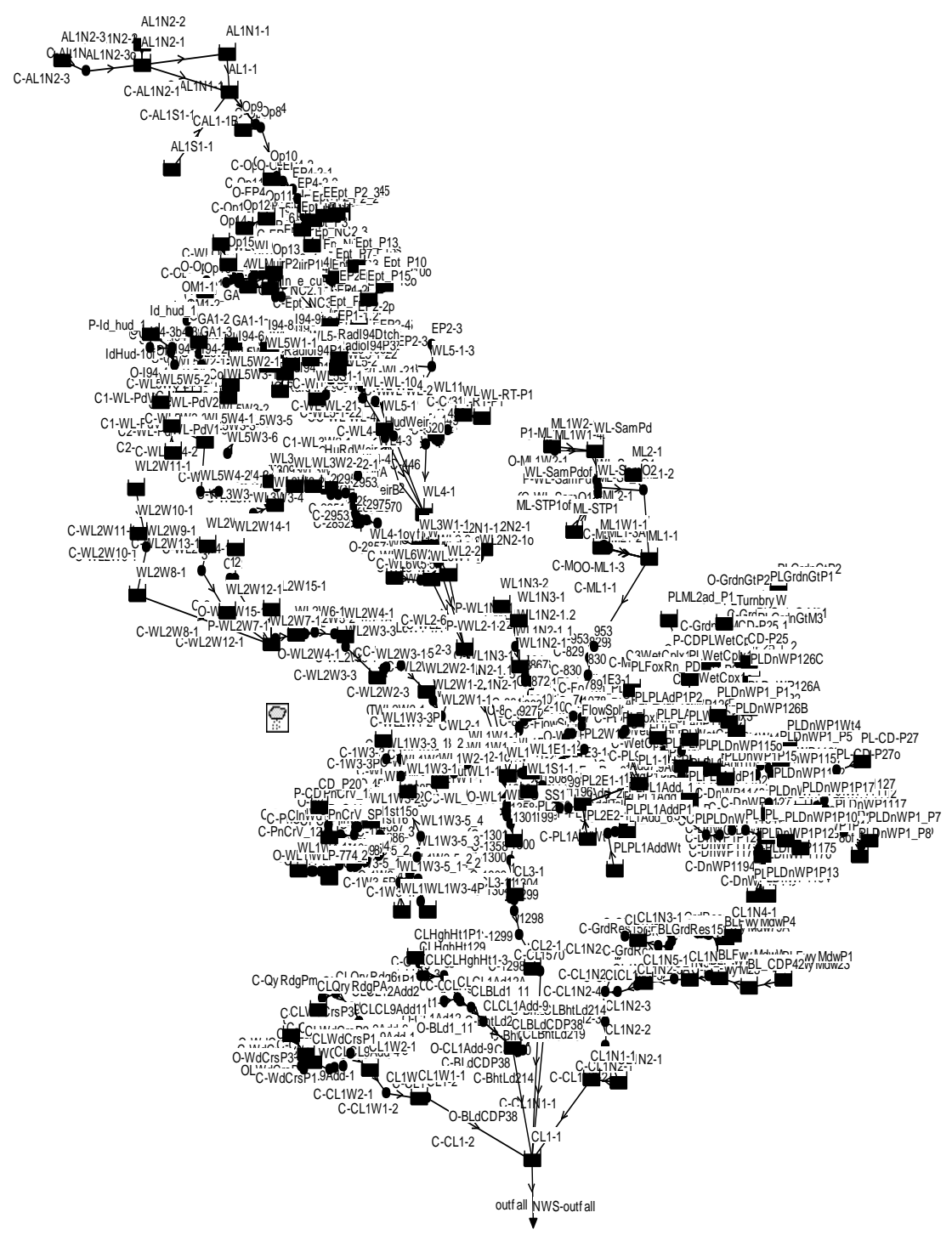

Figure 2 EPA SWMM model of the upper section of the watershed (For illustration only) model used in this study. The model section used in this study includes 208 subcatchments and 525 nodes (Junction nodes 353, Storage nodes 172) and 626 links. 


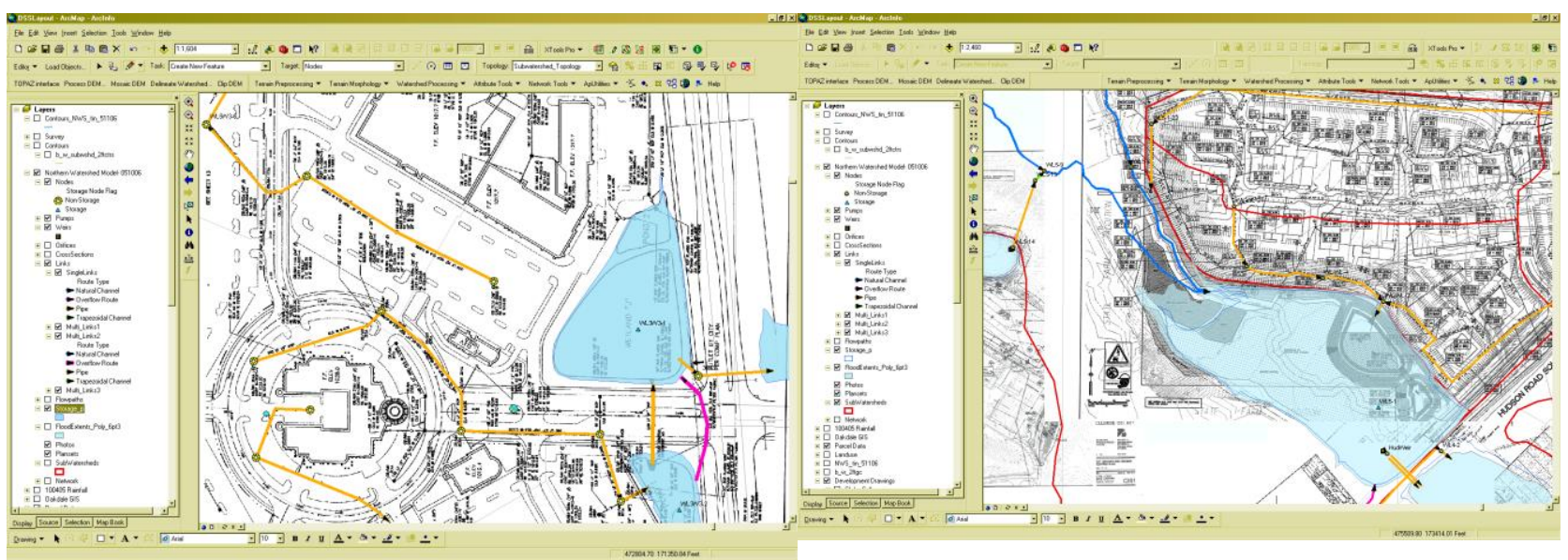

Figure 3 Example of development and grading plans used to generate landuse parameters and geometric features in the model.

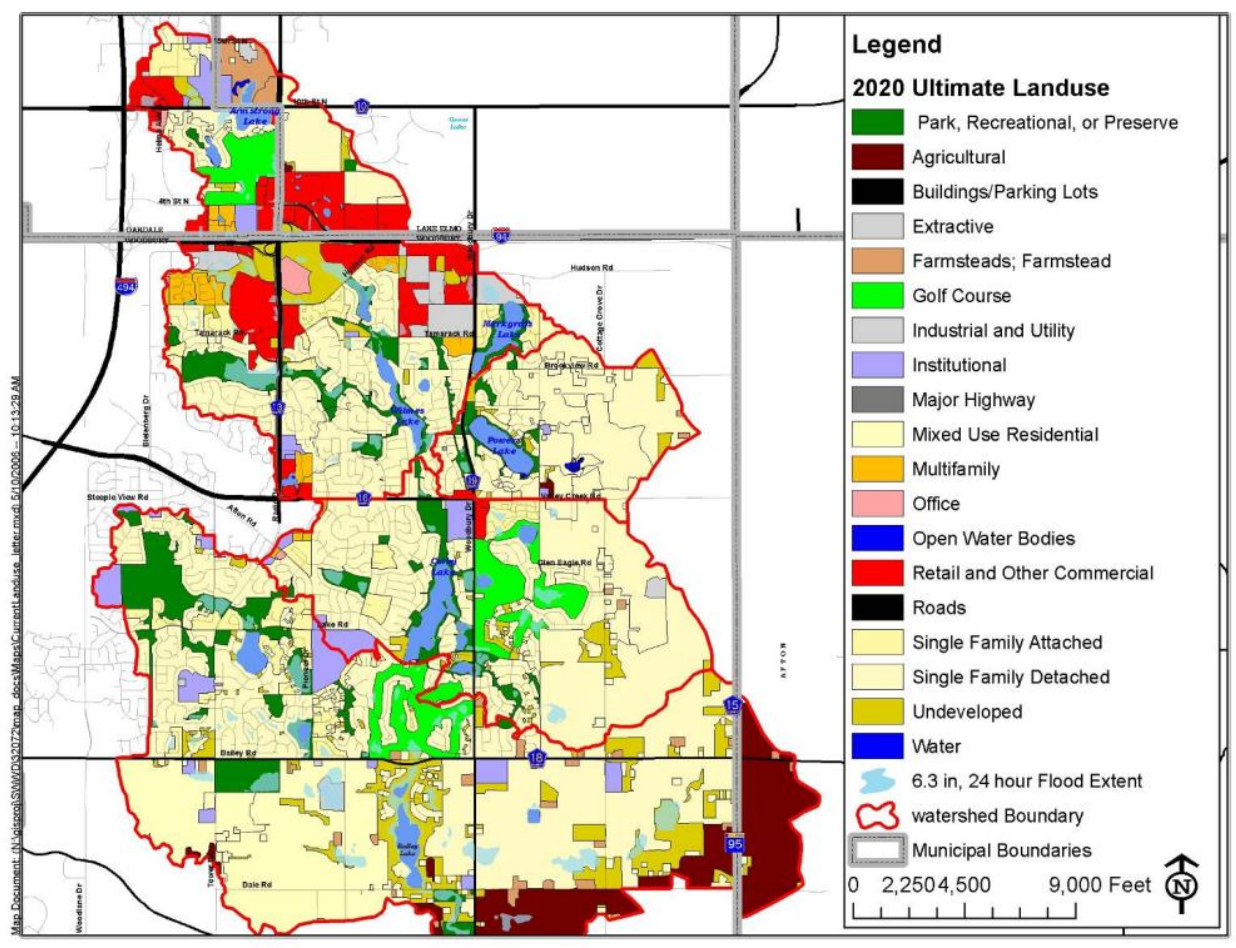

Figure 4 Example layer of a landuse information that was used to generate model parameters. This landuse is map is based on plans developed by the Minnesota Metropolitan Council that is responsible for zone and planning the future growth of the Cities in MN, USA. 
Additional Model Development and related information:

Hettiaracchchi, S, and W. Johnson (2006), Stormwater modelling Report, HDR Project No. 32072, [available online:

http://www.swwdmn.org/pdf/projects/completed/2006\%20Stormwater\%20Modeling\%20Report_HD R.pdf]

Model related reports:

http://www.swwdmn.org/pdf/projects/completed/2006\%20Stormwater\%20Modeling\%20Rep ort_HDR.pdf

The following is an additional presentation that discusses flood mitigation projects analysed using this model.

Hettiarachchi. S, Beduhn. R, Christopherson. J Moore. M, Managing Surface Water for Flood Damage Reduction, World Water and Environmental Resources Congress 2005, May 15-19, 2005 | Anchorage, Alaska, United States, doi-10.1061/40792(173)321

Many of the projects listed here are based on using this model.

http://www.swwdmn.org/projects/ 


\section{$2 \quad$ Analysis for the RCP 4.5 scenario}

Additional analysis was complete for the case of RCP 4.5, looking at a temperature change of $3^{0} \mathrm{C}$. The following table illustrates that the trend in results are similar to the RCP 8.5 scenario for all cases as expected. Understandably, the impact to flood depths is not as significant as when looking at a $5^{0} \mathrm{C}$ increase in temperature as presented in the main paper.

Table 1- Results showing normalized flood depths around the mean at each location for a projected temperature increase of $3^{0} \mathrm{C}$.

\begin{tabular}{llllll} 
& \multicolumn{2}{l}{ Current (normalized) } \\
& $\mathrm{A}$ & $\mathrm{B}$ & $\mathrm{D}$ & $\mathrm{C}$ & $\mathrm{G}$ \\
\cline { 2 - 6 } Q1-10 & 0.58 & 0.15 & 0.65 & 0.53 & 0.33 \\
Q1-50 & -0.28 & -0.07 & -0.08 & -0.11 & -0.16 \\
Q1-90 & -0.31 & -0.10 & -0.23 & -0.24 & -0.37 \\
Q3-10 & -0.14 & -0.04 & -0.19 & -0.12 & -0.07 \\
Q3-50 & -0.03 & -0.01 & -0.18 & -0.08 & 0.03 \\
Q3-90 & 0.18 & 0.07 & 0.03 & 0.01 & 0.24 \\
\hline
\end{tabular}

Projected patterns (normalized)

\begin{tabular}{llllll} 
& $\mathrm{A}$ & $\mathrm{B}$ & $\mathrm{D}$ & $\mathrm{C}$ & $\mathrm{G}$ \\
\cline { 2 - 6 } Q1-10 & 0.60 & 0.16 & 0.67 & 0.54 & 0.33 \\
Q1-50 & -0.21 & -0.06 & -0.05 & -0.04 & -0.09 \\
Q1-90 & -0.31 & -0.10 & -0.19 & -0.21 & -0.38 \\
Q3-10 & -0.05 & -0.02 & -0.15 & -0.06 & 0.03 \\
Q3-50 & 0.11 & 0.02 & -0.07 & -0.02 & 0.16 \\
Q3-90 & 0.27 & 0.10 & 0.08 & 0.06 & 0.25 \\
\hline Change & in & & & & \\
Mean & 0.07 & 0.02 & 0.05 & 0.04 & 0.05 \\
\hline
\end{tabular}

Projected patterns and volumes (normalized)

\begin{tabular}{llllll} 
& $\mathrm{A}$ & $\mathrm{B}$ & $\mathrm{D}$ & $\mathrm{C}$ & $\mathrm{G}$ \\
\cline { 2 - 6 } Q1-10 & 0.98 & 0.38 & 1.36 & 0.73 & 0.49 \\
Q1-50 & 0.34 & 0.14 & 0.04 & 0.09 & 0.25 \\
Q1-90 & 0.04 & 0.03 & -0.15 & -0.15 & -0.09 \\
Q3-10 & 0.47 & 0.16 & 0.15 & 0.03 & 0.27 \\
Q3-50 & 0.91 & 0.36 & 0.60 & 0.23 & 0.34 \\
Q3-90 & 0.91 & 0.36 & 0.60 & 0.23 & 0.34 \\
\hline Change & in & & & & \\
Mean & 0.61 & 0.24 & 0.44 & 0.19 & 0.27 \\
\hline
\end{tabular}




\section{$3 \quad$ Peak Flood Depth Comparison}

Table 2 Percent change in flood depths at all reference points

Impact on flood depth from projected temporal pattern

\begin{tabular}{lllrrrrr} 
& A & B & C & E & D & \multicolumn{1}{c}{ F } & \multicolumn{1}{c}{ G } \\
\hline Q1-10 & $1 \%$ & $1 \%$ & $1 \%$ & $0 \%$ & $2 \%$ & $3 \%$ & $0 \%$ \\
Q1-50 & $3 \%$ & $3 \%$ & $20 \%$ & $8 \%$ & $8 \%$ & $1 \%$ & $7 \%$ \\
Q1-90 & $0 \%$ & $0 \%$ & $12 \%$ & $10 \%$ & $13 \%$ & $1 \%$ & $-1 \%$ \\
Q3-10 & $4 \%$ & $5 \%$ & $19 \%$ & $10 \%$ & $16 \%$ & $2 \%$ & $9 \%$ \\
Q3-50 & $5 \%$ & $8 \%$ & $18 \%$ & $10 \%$ & $35 \%$ & $2 \%$ & $9 \%$ \\
Q3-90 & $4 \%$ & $5 \%$ & $16 \%$ & $7 \%$ & $12 \%$ & $15 \%$ & $1 \%$ \\
\hline
\end{tabular}

Impact on flood depth from projected volume and temporal pattern

\begin{tabular}{llllrlrl} 
& $\mathrm{A}$ & $\mathrm{B}$ & $\mathrm{C}$ & $\mathrm{D}$ & $\mathrm{E}$ & $\mathrm{F}$ & $\mathrm{G}$ \\
\hline Q1-10 & $13 \%$ & $40 \%$ & $53 \%$ & $95 \%$ & $21 \%$ & $108 \%$ & $12 \%$ \\
Q1-50 & $31 \%$ & $51 \%$ & $74 \%$ & $69 \%$ & $37 \%$ & $57 \%$ & $25 \%$ \\
Q1-90 & $17 \%$ & $34 \%$ & $49 \%$ & $37 \%$ & $27 \%$ & $9 \%$ & $35 \%$ \\
Q3-10 & $27 \%$ & $46 \%$ & $61 \%$ & $147 \%$ & $59 \%$ & $76 \%$ & $22 \%$ \\
Q3-50 & $26 \%$ & $52 \%$ & $68 \%$ & $173 \%$ & $57 \%$ & $119 \%$ & $17 \%$ \\
Q3-90 & $23 \%$ & $48 \%$ & $78 \%$ & $140 \%$ & $49 \%$ & $170 \%$ & $8 \%$ \\
\hline
\end{tabular}

Table $4 \quad$ Runoff volume comparison from Modelling results

Comparison of total runoff volume for the whole catchment generated during model runs for Q1-50 and Q3-50 events.

\section{Runoff Volume \\ Comparison}

\begin{tabular}{lrrl}
\hline \multicolumn{1}{l}{160} & $\mathrm{~mm}$ & 24 & hours \\
& & & \\
\hline Total modelled runoff for & $\mathrm{Q} 1-50$ & $1,586,102$ & $\begin{array}{l}\text { Cu. } \\
\text { Meters } \\
\text { Cu. }\end{array}$ \\
Total modelled runoff for & Q3-50 & $1,736,527$ & Meters \\
& & & Cu. \\
& & 150,425 & Meters \\
\hline Difference & $9.5 \%$ &
\end{tabular}

